\title{
Sulfuric Acid Processing for the Production of Chromite Concentrates from Donskoy Ore-Mining and Processing Plant Slurry Tails
}

\author{
Rinat A. Abdulvaliyev, Sergey S. Gladyshev, \\ Nazym K. Akhmadiyeva*, Kulzhaiyk O. Beisembekova, \\ Saltanat A. Omarova, Alfiyam I. Manapova, \\ Galiyat S. Ruzakhunova and Marina N. Kvyatkovskaya \\ Institute of Metallurgy and Ore beneficiation \\ 29/133, Shevchenko Str., Almaty, 050010, Kazakhstan
}

Received 19.07.2016, received in revised form 19.09.2016, accepted 11.12.2016

Research on the technology for beneficiation of sludge tails of the processing of chromite containing ore Donskoi ore mining and processing enterprise of the Republic of Kazakhstan was provided. Physical and chemical analysis of sludge tails and processing by-products was shown. The technological scheme for processing of sludge tails includes: preactivationof tails in $120 \mathrm{~g} / \mathrm{dm}^{3}$ slurry soda solution, at a liquid to solid ratio of 10 at $120{ }^{\circ} \mathrm{C}$ for 90 minutes; sulfuric acid leaching with30\%ammonium hydrosulfate solution and gravity concentration on centrifugal separator. The final chromite concentrate contained $59.2 \% \mathrm{Cr}_{2} \mathrm{O}_{3}$, with a recovery of $86.8 \%$.

Keywords: beneficiationof sludge tails, chromite, concentrate, centrifugal separator, autoclave.

DOI: $10.17516 / 1998-2836-2016-9-4-515-524$.

(C) Siberian Federal University. All rights reserved

* Corresponding author E-mail address: naz-ank@inbox.ru 


\title{
Сернокислотная переработка шламовых хвостов Донского ГОКа с получением хромитового концентрата
}

\author{
Р.А. Абдулвалиев, С.В. Гладышев, \\ Н.К. Ахмадиева*, К.О. Бейсембекова, С.А. Омарова, \\ А.И. Манапова, Г.С. Рузахунова, М.Н. Квятковская \\ Институт металлургии и обогащения \\ Казахстан, 050010, Алматы, ул. Шевченко, 29/133
}

Проведены исследования обогащения шламовых хвостов переработки хромитовой руды Донского горно-обогатительного комбината Республики Казахстан. Представлен физикохимический анализ шламовых хвостов и промпродуктов переработки. Разработана технологическая схема переработки, включающая операции предварительной активации

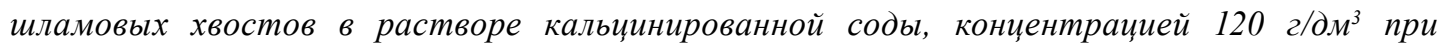
температуре $120{ }^{\circ} \mathrm{C}$, Т:Ж=1,0:10,0 и продолжительности 90 мин, сернокислотное выщелачивание в 30\%-м растворе гидросульфата аммония и гравитационное обогащение на иентробежном сепараторе. В результате переработки получен хромитовый кониентрат с содержанием $\mathrm{Cr}_{2} \mathrm{O}_{3} 59,2 \%$ при извлечении $\mathrm{Cr}_{2} \mathrm{O}_{3}$ в конщентрат 86,8\%.

Ключевые слова: обогащение, иламовые хвосты, хромит, кониентрат, иентробежный сепаратор, автоклав.

\section{Введение}

Важность решения задачи вовлечения в переработку отходов продуктов обогащения связана не только с экологией, но и с потребностью увеличения производства хрома. С 2005 по 2012 г. мировой объем производства хрома, по данным Международной ассоциации по развитию хромовой промышленности The International Chromium Development Association (ICDA), увеличился примерно с 18 до 24 млн т. Наиболее значимые экспортеры хромовой руды - Южная Африка, Турция, Иран, Индия, Оман, Пакистан и Казахстан [1].

Крупным импортером хромовой руды признан Китай. Преимуществом Китая является значительное потребление феррохрома. До недавнего времени в южноафриканской феррохромовой промышленности наблюдался неуклонный рост для удовлетворения увеличивающегося спроса со стороны Европы, Японии, Китая и Кореи, но теперь большинство южноафриканских производств малорентабельно из-за низких цен на феррохром при высоких затратах. В то же время, по оценке китайской консалтинговой компании The Beijing Axis, Китай владеет менее чем $1 \%$ хрома мировых запасов. Тем не менее благодаря увеличению роста спроса на нержавеющую сталь и относительно низким производственным затратам внутренние мощности феррохрома в Китае неуклонно растут в течение последнего десятилетия. В 2011 г. Китай использовал 3,5 млн т высокоуглеродистого феррохрома, при этом более половины его было отечественного производства. Для восполнения хромсодержащего сырья Китай заинтересован в новых поставках, в том числе из Казахстана. 
Предприятием, осуществляющим добычу и обогащение хромового сырья в Казахстане, выступает Донской ГОК. Гравитационная технология обогащения хромовой руды позволяет получать хромовый концентрат из крупных и средних фракций, а мелкодисперсный шлам практически не обогащается из-за трудности разделения сложных минералов на хромовые концентраты и пустую породу [2, 3]. Доизвлечение хрома из шламов с учетом существующего спроса на хромовые концентраты является важной практической задачей.

\section{Результаты и обсуждение}

В работе были использованы шламовые хвосты обогащения хромитовых руд обогатительной фабрики Донского горно-обогатительного комбината Республики Казахстан.

Химический состав исходной пробы и полученных продуктов установлен методом рентгенофлюоресцентного анализа на спектрометре с волновой дисперсией Venus 200 PANalyical B.V. (PANalytycal B.V., Голландия).

Химический анализ шламовых хвостов приведен в табл. 1.

Рентгенофазовый анализ продуктов проводили на дифрактометре D8 Advance (BRUKER), излучение $\alpha-\mathrm{Cu}$.

Результаты рентгенофазового анализа шламовых хвостов Донского ГОКа представлены в табл. 2.

Минералогический анализ проб проводили под микроскопом МИН-8 при увеличении 320x, а также под микроскопом OLYMPUS при увеличении 200x, 400x в проходящем свете в иммерсионной среде и в полированных шлифах в отраженном свете под инвертированным микроскопом Leica. Микрофотографии проб в отраженном свете изготовлены при увеличении 300x под инвертированным микроскопом Leica, в проходящем свете под микроскопом OLYMPUS при увеличении 200x, 400x с помощью программы Stream Basic R (рис. 1).

Таблица 1. Химический состав шламовых хвостов хромитовой руды

\begin{tabular}{|c|c|c|c|}
\hline Наименование & Содержание, $\%$ & Наименование & Содержание, $\%$ \\
\hline $\mathrm{Cr}_{2} \mathrm{O}_{3}$ & 25,47 & $\mathrm{Cu}$ & 0,008 \\
\hline $\mathrm{Fe}_{2} \mathrm{O}_{3}$ & 9,1 & $\mathrm{~Pb}$ & 0,05 \\
\hline $\mathrm{SiO}_{2}$ & 21,53 & $\mathrm{As}$ & 0,025 \\
\hline $\mathrm{AI}_{2} \mathrm{O}_{3}$ & 1,51 & $\mathrm{Sb}$ & 0,23 \\
\hline $\mathrm{H}_{2} \mathrm{O}$ (связанная) & 7,8 & $\mathrm{~K}$ & 0,05 \\
\hline $\mathrm{CaO}$ & 0,75 & $\mathrm{Na}$ & 0,05 \\
\hline $\mathrm{MgO}$ & 29,4 & $\mathrm{P}$ & 0,008 \\
\hline $\mathrm{MnO}_{2}$ & 0,053 & $\mathrm{C}$ & $<0,2$ \\
\hline $\mathrm{S}_{\text {общ }}$ & 0,1 & $\mathrm{Ag}, \Gamma / \mathrm{T}$ & $<2,0$ \\
\hline $\mathrm{S}_{\text {сульф. }}$ & $<0,1$ & $\mathrm{Au}, \Gamma / \mathrm{T}$ & $<0,05$ \\
\hline $\mathrm{Zn}$ & 0,1 & $\mathrm{Ni}$ & 0,28 \\
\hline $\mathrm{Co}$ & 0,02 & & \\
\hline
\end{tabular}


Таблица 2. Рентгенофазовый состав шламовых хвостов

\begin{tabular}{|l|l|c|}
\hline \multicolumn{1}{|c|}{ Наименования фаз } & \multicolumn{1}{c|}{ Формула } & \multicolumn{1}{c|}{$\%$} \\
\hline Антигорит & $\mathrm{Mg}_{3} \mathrm{Si}_{2} \mathrm{O}_{5}(\mathrm{OH})_{4}$ & 41.8 \\
\hline Алюможелезистый магнезит & $\mathrm{MgFeAlO}_{4}$ & 29.7 \\
\hline Хромит магния & $\mathrm{MgCr}_{2} \mathrm{O}_{4}$ & 5.1 \\
\hline Клинохлор & $\mathrm{Mg}_{6} \mathrm{Si}_{4} \mathrm{O}_{10}(\mathrm{OH})_{8}$ & 4.8 \\
\hline Железистый оксид кальция & $\mathrm{CaFe}_{2} \mathrm{O}_{4}$ & 3.9 \\
\hline Алюможелезистый оксид кальция & $\mathrm{Ca}_{2} \mathrm{Fe}_{1.28} \mathrm{Al}_{0.72} \mathrm{O}_{5}$ & 1.7 \\
\hline Браувнмиллерит & $\mathrm{Fe}_{1.33} \mathrm{~A}_{1.67} \mathrm{Ca}_{2} \mathrm{O}_{5}$ & 0.3 \\
\hline Алюмокальциевый силикат & $\mathrm{Ca}_{46}\left(\mathrm{Al}_{92} \mathrm{Si}_{100} \mathrm{O}_{384}\right)$ & 0.3 \\
\hline Алюмомагниевый силикат кальция & $\mathrm{Ca}_{23.20 \mathrm{Mg}_{22.4}(\mathrm{~A} 192 \mathrm{Si100O} 384)}$ \\
\hline
\end{tabular}
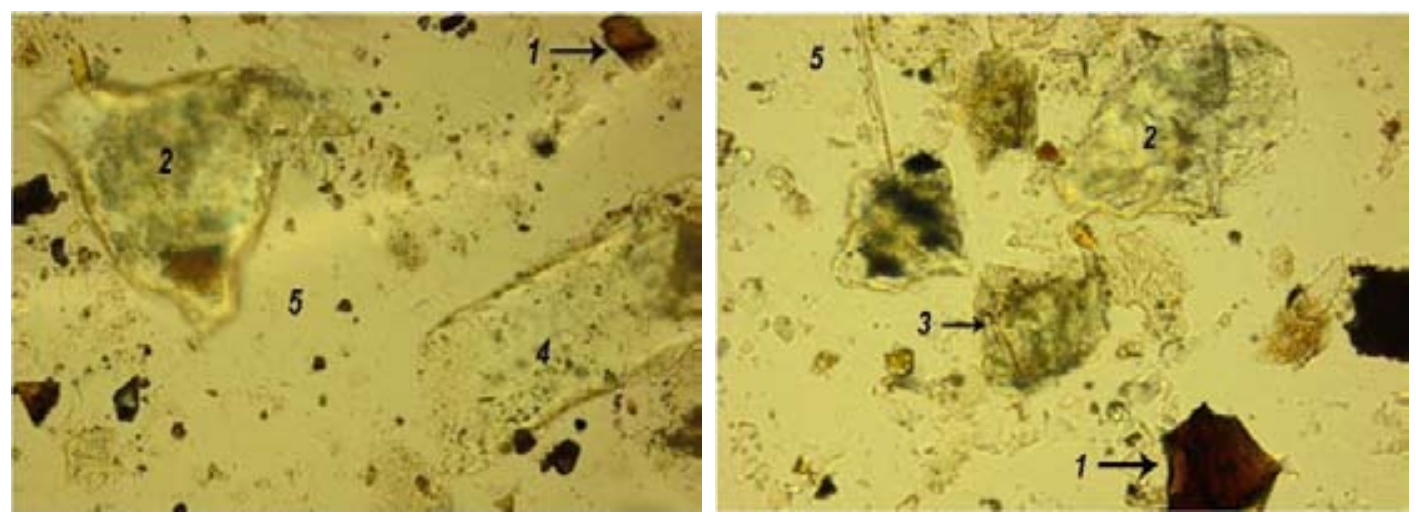

Рис. 1. Минералогический состав шламовых хвостов: 1 - шунгит, 2 - шпинель минералов группы хлоритов; 3 - алюмомагнезиальная шпинель; 4 - антигорит; 5 - иммерсионная среда

Шпинель минералов группы хлоритов (рис. 1, точка 2) представлена шамозитом (Fe, $\mathrm{Mg}, \mathrm{Al})$ $(\mathrm{Si}, \mathrm{Al})_{4} \mathrm{O}_{10}(\mathrm{OH})_{8}$ - пластинчатые зерна желто-зеленого цвета с плеохроизмом (плеохроизм от зеленого до светло-желтого).

Алюмомагнезиальная шпинель (рис. 1, точка 3) состава - $\mathrm{Fe}, \mathrm{Mg}, \mathrm{Al}, \mathrm{Cr}$ - зерна от бурокоричневого до красновато-коричневого цвета, изотропные, излом раковистый.

Антигорит $\mathrm{Mg}_{3} \mathrm{Si}_{2} \mathrm{O}_{5}(\mathrm{OH})_{4}$ (рис. 1, точка 4) - анизотропные бесцветные зерна с волокнистой структурой. Оптически двуосный отрицательный $2 \mathrm{~V}(-)$ с показателем преломления N 1,550.

Термический анализ шлама был проведен с использованием прибора синхронного термического анализа STA 449 F3 Jupiter. Перед нагревом печное пространство откачивалось и затем продувалось инертным газом. Нагрев проб осуществлялся со скоростью $10{ }^{\circ} \mathrm{C} / \mathrm{Mин}$ в атмосфере высокоочищенного аргона. Объем поступающего газа варьировался в зависимости от химического анализа пробы и выдерживался в пределах 80-90 мл/мин. Охлаждение велось до $300{ }^{\circ} \mathrm{C}$ со скоростью $15{ }^{\circ} \mathrm{C} /$ мин. Обработка результатов, полученных с помощью STA 449 F3 Jupiter, производилась посредством программного обеспечения NETZSCH Proteus (рис. 2). 


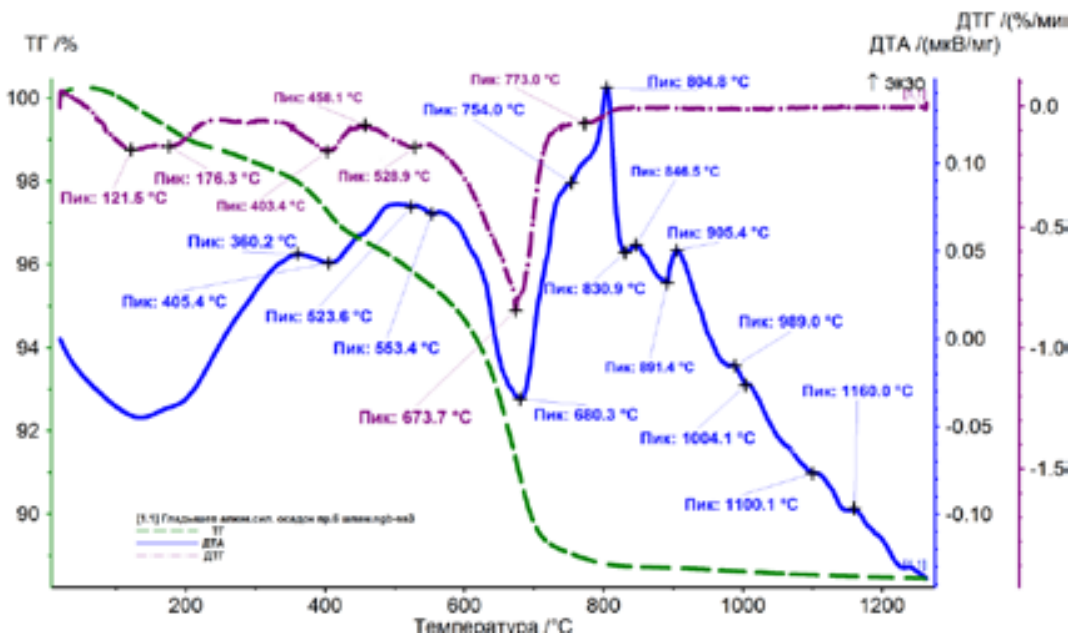

Рис. 2. Термограмма шламовых хвостов

Наиболее интенсивный эффект на кривой ДТА эндотермический, с максимальным развитием при $680{ }^{\circ} \mathrm{C}$, сопровождается снижением массы навески (рис. 2). В сочетании с экзотермическими пиками при 805 и $1160{ }^{\circ} \mathrm{C}$ этот эффект может отражать проявление серпентина. При $680{ }^{\circ} \mathrm{C}$ происходит разрушение структуры минерала с одновременным удалением группы ОН, образование новых минеральных фаз - кристаллического форстерита и рентгеноаморфного энстатита. Экзотермический пик при $805^{\circ} \mathrm{C}$ отражает упорядочение структуры форстерита, а пик при $1160{ }^{\circ} \mathrm{C}$ - кристаллизацию рентгеноаморфного энстатита. Минимум при $403{ }^{\circ} \mathrm{C}$ на кривой ДТГ может быть проявлением дегидратации гидроксидов железа, магния и оксигидроксида хрома. Слабый максимум на этой же кривой при $458{ }^{\circ} \mathrm{C}$ может отражать окисление двухвалентного железа в магнетите или хромите остаточным кислородом. Сочетание эндотермического эффекта с экстремумом при $680{ }^{\circ} \mathrm{C}$, эндотермического эффекта с экстремумом при $831{ }^{\circ} \mathrm{C}$ и экзотермического эффекта при $847{ }^{\circ} \mathrm{C}$ можно трактовать как проявление какого-либо магнезиального хлорита пеннина, кеммерерита, клинохлора. Сочетание экзотермического эффекта с пиком при $360{ }^{\circ} \mathrm{C}$, эндотермических эффектов с экстремумами при 680 и $745{ }^{\circ} \mathrm{C}$, экзотермического эффекта с пиком при $905{ }^{\circ} \mathrm{C}$, возможно, отражает наличие в пробе минерала маргарит $\mathrm{CaO}_{2} \mathrm{Al}_{2} \mathrm{O}_{3} 2 \mathrm{SiO}_{2} \mathrm{H}_{2} \mathrm{O}$. При $360{ }^{\circ} \mathrm{C}$ происходит окисление примеси закисного железа, при 680 и $745{ }^{\circ} \mathrm{C}$ - удаление гидроксильной воды и разрушение решетки, при $905{ }^{\circ} \mathrm{C}$ идет кристаллизация продуктов распада. Известно [4], что нагревание хлорита до температур, превышающих температуру экзотермического эффекта, приводит к образованию шпинелей. В [5] даны сведения о том, что после дегидратации нескольких гидроксидов образуется твердый раствор шпинелидов. Процесс отображается на термограмме экзотермическим эффектом. Основываясь на этих данных, можно предположить, что экзотермические эффекты, кроме вышеописанных процессов, отражают еще и реакции образования твердых растворов хромшпинелидов из продуктов дегидратации фазовых составляющих изучаемой пробы. 


\section{Разработка технологии переработки шламовых хвостов с получением хромитового концентрата}

Разработана технология переработки шламовых хвостов с получением хромитового концентрата, включающая предварительную активацию в содовом растворе, сернокислотное выщелачивание и гравитационное обогащение. Обогащение шламовых хвостов проводили методами химического обогащения, путем выщелачивания в сернокислом растворе и гравитационного обогащения.

Для активации шламовые хвосты обрабатывали раствором кальцинированной соды концентрацией 120 г/дм³ при температурах $100-240{ }^{\circ} \mathrm{C}, \mathrm{T:Ж=1,0:10,0} \mathrm{и} \mathrm{продолжительности} 90$ мин. Исследования проводили в автоклаве емкостью 1,8 дм³ $^{3}$ магнитной мешалкой и системами загрузки материалов и отбора проб (рис. 3).

Химический анализ активированного шлама показал (табл. 3), что в результате активации количественный состав проб изменяется незначительно, за исключением снижения содержания кальция. В то же время, как следует из данных рентгенофазового анализа, фазовый состав проб изменяется (табл. 4), исчезают фазы, содержащие оксид кальция, меняются количественные соотношения магнийсодержащих фаз.

Анализ приведенных данных зависимости фазового состава шламовых хвостов от температуры при активации показывает, что при температуре $120{ }^{\circ} \mathrm{C}$ практически все основные изменения фазового состава заканчиваются.

После активации шламовые хвосты перерабатывали методом сернокислотного выщелачивания при температуре $95-100{ }^{\circ} \mathrm{C}$ в регенерируемом растворе гидросульфата аммония $\mathrm{NH}_{4} \mathrm{HSO}_{4}$.

Для регенерации сернокислотного выщелачивающего раствора - гидросульфата аммония известен способ [6] термического разложения сульфата аммония на гидросульфат и аммиак по реакции

$$
\left(\mathrm{NH}_{4}\right)_{2} \mathrm{SO}_{4}=\mathrm{NH}_{4} \mathrm{HSO}_{4}+\mathrm{NH}_{3}
$$

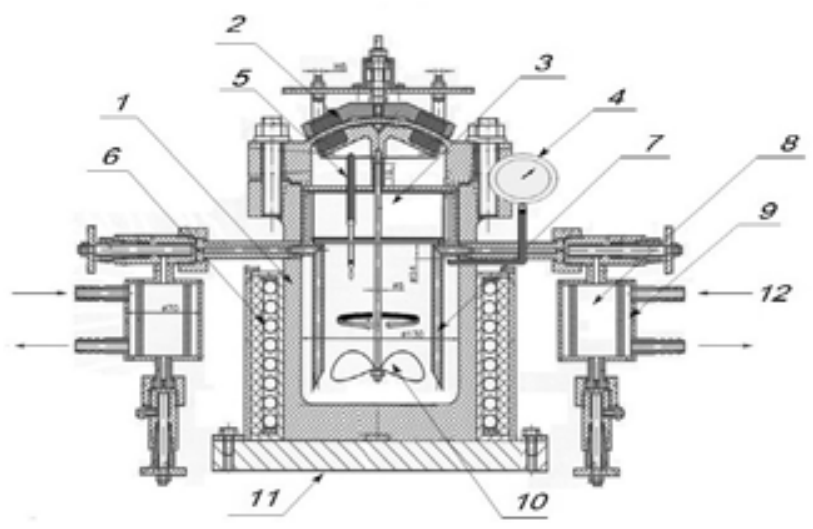

Рис. 3. Автоклав: 1 - корпус автоклава, 2 - крышка автоклава, 3 - емкости для загрузки навески, 4 манометр, 5 - чехол термопары, 6 - нагревательный элемент печи, 7 - пробоотборник, 8 - камера отбора проб, 9 - холодильник, 10 - магнитная мешалка, 11 - станина, 12 - подача воды для охлаждения 


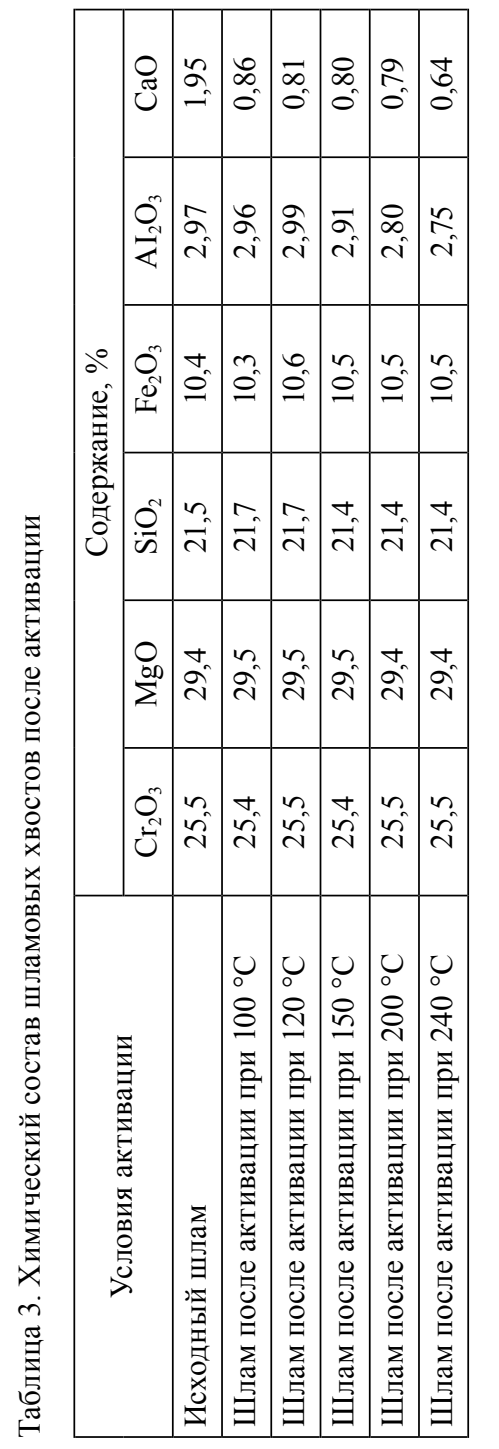

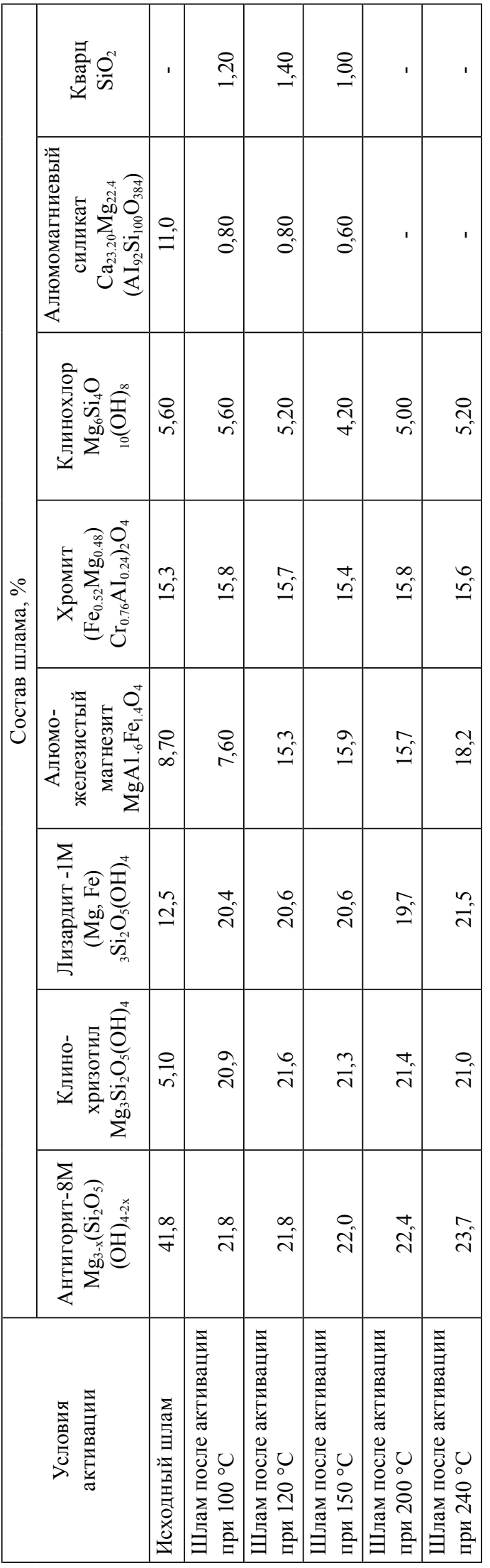


В проведенных исследованиях при выщелачивании шламовых хвостов использован раствор гидросульфата аммония концентрацией 30,0 \%. Выщелачивание проводили при температуре $95{ }^{\circ} \mathrm{C}$ в течение 60 мин. Кроме раствора гидросульфата аммония для выщелачивания применяли раствор $5 \% \mathrm{H}_{2} \mathrm{SO}_{4}$ и раствор, состоящий из $30 \% \mathrm{NH}_{4} \mathrm{HSO}_{4}+1 \% \mathrm{H}_{2} \mathrm{O}_{2}$. Наилучшие результаты выщелачивания получены при использовании раствора выщелачивания с $30 \%$ $\mathrm{NH}_{4} \mathrm{HSO}_{4}$, в этом случае содержание хрома в кеке (черновом хромитовом концентрате) составило 38,4 \% $\mathrm{Cr}_{2} \mathrm{O}_{3}$ при выходе кека 65,5 \% от массы исходных шламовых хвостов (табл. 5).

Кеки выщелачивания направили на обогащение на гравитационном сепараторе KNELSON, в результате были получены хромитовые концентраты, состав которых приведен в табл. 6 .

Материальный баланс обогащения кека после выщелачивания в растворе $30 \% \mathrm{NH}_{4} \mathrm{HSO}_{4}$ на центробежном сепараторе отражен в табл. 7.

Таблица 5. Кек (черновой концентрат) от выщелачивания шламовых хвостов

\begin{tabular}{|c|c|c|c|c|c|c|c|c|c|c|c|c|}
\hline \multirow{2}{*}{$\begin{array}{l}\text { Номер } \\
\text { п.п. }\end{array}$} & \multirow{2}{*}{$\begin{array}{c}\text { Условия } \\
\text { выщелачивания }\end{array}$} & \multicolumn{2}{|c|}{$\mathrm{Cr}_{2} \mathrm{O}_{3}$} & \multicolumn{2}{|c|}{$\mathrm{Fe}_{2} \mathrm{O}_{3}$} & \multicolumn{2}{|c|}{$\mathrm{MgO}$} & \multicolumn{2}{|c|}{$\mathrm{SiO}_{2}$} & \multicolumn{2}{|c|}{$\mathrm{AI}_{2} \mathrm{O}_{3}$} & \multirow{2}{*}{$\begin{array}{l}\text { Выход } \\
\text { кека, \% }\end{array}$} \\
\hline & & $\%$ & $\varepsilon, \% *$ & $\%$ & $\varepsilon, \%$ & $\%$ & $\varepsilon, \%$ & $\%$ & $\varepsilon, \%$ & $\%$ & $\varepsilon, \%$ & \\
\hline 1 & Исходный шлам & 25,5 & 100,0 & 10,5 & 100,0 & 30,0 & 100,0 & 22,7 & 100,0 & 2,74 & 100,0 & \\
\hline 2 & $\begin{array}{l}\text { Кек от выщелачивания } \\
\text { в } 5 \% \mathrm{H}_{2} \mathrm{SO}_{4}\end{array}$ & 32,1 & 95,4 & 9,94 & 69,9 & 18,8 & 46,3 & 30,7 & 100,0 & 3,04 & 82,1 & 75,0 \\
\hline 3 & $\begin{array}{l}\text { Кек от выщелачивания } \\
\text { в } 30 \% \mathrm{NH}_{4} \mathrm{HSO}_{4}\end{array}$ & 38,4 & 96,8 & 9,25 & 39,9 & 7,08 & 10,7 & 34,0 & 70,0 & 4,56 & 75,0 & 65,5 \\
\hline 4 & $\begin{array}{l}\text { Кек от выщела-чивания } \\
\text { в } 30 \% \mathrm{NH}_{4} \mathrm{HSO}_{4}+ \\
1 \% \mathrm{H}_{2} \mathrm{O}_{2}\end{array}$ & 36,9 & 95,5 & 7,47 & 33,5 & 8,07 & 12,1 & 40,8 & 84,6 & 3,2 & 55,7 & 67,1 \\
\hline
\end{tabular}

$\varepsilon, \%$ * извлечение компонента в состав кека (чернового концентрата)

Таблица 6. Результаты центробежной сепарации кеков

\begin{tabular}{|c|c|c|c|c|c|c|c|c|}
\hline \multirow{2}{*}{$\begin{array}{c}\text { Наименования } \\
\text { кеков }\end{array}$} & \multicolumn{6}{|c|}{ Состав хромитового концентрата, \% } & \multirow{2}{*}{$\begin{array}{c}\text { Извлечение } \\
\mathrm{Cr}_{2} \mathrm{O}_{3} \text { в } \\
\text { концентрат, \% }\end{array}$} & \multirow{2}{*}{$\begin{array}{c}\text { Выход } \\
\text { концентрата, \% }\end{array}$} \\
\hline & $\mathrm{Cr}_{2} \mathrm{O}_{3}$ & $\mathrm{MgO}$ & $\mathrm{SiO}_{2}$ & $\mathrm{Fe}_{2} \mathrm{O}_{3}$ & $\mathrm{AI}_{2} \mathrm{O}_{3}$ & $\mathrm{CaO}$ & & \\
\hline 2 & 59,2 & 9,1 & 12,4 & 13,1 & 4,63 & 0,21 & 86,8 & 32,9 \\
\hline 3 & 53,4 & 9,80 & 19,1 & 13,1 & 4,10 & 0,14 & 7,62 & 32,4 \\
\hline 4 & 42,6 & 18,7 & 23,0 & 11,0 & 3,67 & 0,20 & 72,7 & 36,9 \\
\hline
\end{tabular}

Таблица 7. Материальный баланс обогащения кека после выщелачивания в растворе $30 \% \mathrm{NH}_{4} \mathrm{HSO}_{4} \mathrm{Ha}$ центробежном сепараторе KNELSON

\begin{tabular}{|c|c|c|c|c|c|}
\hline \multirow{2}{*}{$\begin{array}{c}\text { Наименование } \\
\text { Продуктов }\end{array}$} & \multicolumn{2}{|c|}{ Выход } & Содержание, \% & Произведение & Извлечение, \% \\
\cline { 1 - 6 } & $\Gamma$ & $\%$ & $\mathrm{Cr}_{2} \mathrm{O}_{3}$ & $\mathrm{Cr}_{2} \mathrm{O}_{3}$ & $\mathrm{Cr}_{2} \mathrm{O}_{3}$ \\
\hline Концентрат & 49,4 & 32,9 & 59,2 & 1947,68 & 86,8 \\
\hline Хвосты & 100,7 & 67,1 & 4,35 & 291,7 & 13,2 \\
\hline Итого: & 150 & 100,0 & & 2239,38 & 100,0 \\
\hline
\end{tabular}


Таблица 8. Рентгенофазовый анализ продуктов обогащения кека после выщелачивания в растворе 30 \% $\mathrm{NH}_{4} \mathrm{HSO}_{4}$

\begin{tabular}{|c|c|c|c|}
\hline \multirow{2}{*}{ Продукты } & \multicolumn{3}{|c|}{ Содержания фаз, \% } \\
\cline { 2 - 4 } & $\begin{array}{c}\text { Хромит } \\
(\mathrm{Fe} 0.52 \mathrm{Mg} 0.48)(\mathrm{Cr} 0.76 \mathrm{~A} 10.24) 2 \mathrm{O} 4\end{array}$ & $\begin{array}{c}\text { Каолинит } \\
\mathrm{Al}_{2} \mathrm{Si}_{2} \mathrm{O}_{5}(\mathrm{OH})_{4}\end{array}$ & $\begin{array}{c}\text { Клинохлор } \\
(\mathrm{Mg}, \mathrm{Fe}, \mathrm{Al})_{6}(\mathrm{Si}, \mathrm{Cr})_{4} \mathrm{O}_{10}(\mathrm{OH})_{8}\end{array}$ \\
\hline Концентрат & 100,0 & - & - \\
\hline Хвосты & 10,6 & 44,9 & 44,5 \\
\hline
\end{tabular}

Рентгенофазовый анализ продуктов обогащения кека после выщелачивания в растворе $30 \% \mathrm{NH}_{4} \mathrm{HSO}_{4}$ представлен в табл. 8.

Из данных рентгенофазового и химического анализов следует, что при выщелачивании раствором гидросульфата аммония $30 \% \mathrm{NH}_{4} \mathrm{HSO}_{4}$ шламовых хвостов породообразующие минералы в основном переходят в раствор, а в кеке - черновом концентрате - остаются хромит и хромитсодержащие минералы, коалинит и аморфный кремнезем. Аморфный кремнезем не поддается рентгенофазовому анализу.

При обогащении чернового концентрата на центробежном сепараторе KNELSON получен хромитовый концентрат, состоящий из минерала хромита - $\left(\mathrm{Fe}_{0.52} \mathrm{Mg}_{0.48}\right)\left(\mathrm{Cr}_{0.76} \mathrm{Al}_{0.24}\right)_{2} \mathrm{O}_{4}$.

Таким образом, при обогащении шламовых хвостов по технологии, включающей предварительную активацию в содовом растворе, сернокислоте выщелачивание в растворе гидросульфата аммония и центробежную сепарацию, получен хромитовый концентрат с содержанием 59,2 \% $\mathrm{Cr}_{2} \mathrm{O}_{3}$, при извлечении $\mathrm{Cr}_{2} \mathrm{O}_{3}$ в концентрат 86,8 \%.

\section{Список литературы}

1. Анализ мирового рынка хрома. [Электронный ресурс.] URLhttp://www.metalresearch. ru/world_chromium_analysis.html.(дата обращения 03.02.2016) [Analysis of world market of chromium. Electron resource. URL: http://www.metalresearch.ru/world_chromium_analysis.html

2. Вышегородский Д. Российский хром. Уральский рынок металлов 2015. 9. Электронный pecypc. URL:http://www.urm.ru/ru/75-journal117-article1480 (дата обращения 11.05.2016 [Vyshegorodskij D. Russian chromium. Uralskij rynok metalla 2015. 9. Electronresource. URL:http:// www. urm.ru/ru/75-journal117-article1480

3. УманскийА.Б., КлюшниковА.М. Гидрометаллургическая переработка отвалов серпентина с выделением никелевого концентрата. Труды Международного конгресса «Фундаментальные основы технологий переработки и утилизации техногенных отходов». Россия, г. Екатеринбург, 2012. С. 419 [Umanskij A.B., Klyushnikov A.M. Hydrometallurgical processing of serpentine with extraction of nickel concentrate. Proceedings of the International congress "Fundamental base of technology for processing and recycling of technogenic waste materials". Russia. Yekaterinburg, $2012-419]$

4. Чалый В.П. Гидроокиси металлов. Киев: Наукова думка, 1972. 160 с.[Chalyi V.P. Metalshydrooxides. Kiev: Naukova dumka, 1972, 160 p. (in Russ.)]

5. Иванова В.П. Термическийанализминераловигорныхпород. Ленинград, 1974. 325 с. [IvanovaV.P. Thermalanalysisofmineralsandrocks. Leningrad, 1974. 325 p. (in Russ.)] 
6. Газалеева Г.И., Орлов С.Л., Мушкетов А.А., Сонина Н.А., Братыгин Е.В., Дмитриева Е.Г., Анашкин В.С., Климентеног Г.Н. Разработка технологий обогащения красных шламов Уральского алюминиевого завода. Материалы XVII Международной научно-технической конференции «Научные основы и практика переработки руд и техногенного сырья. Екатеринбург. 2012. C. 16-20. [Gazeleeva G.I., Orlov S.L., Mushketov A.A., Sonina N.A., Bratygin E.V., Dmitrieyeva E.G. Anashkin V.S., Klimentenog G.N. The development of the technology of red mud beneficiation from Ural alumina plant. Proceedings of the XVII International scientific-technical conference "Scientific basis and practice of ore and technogenic materials processing. Yekaterinburg. 2012. P. 1620" (in Russ.)] 